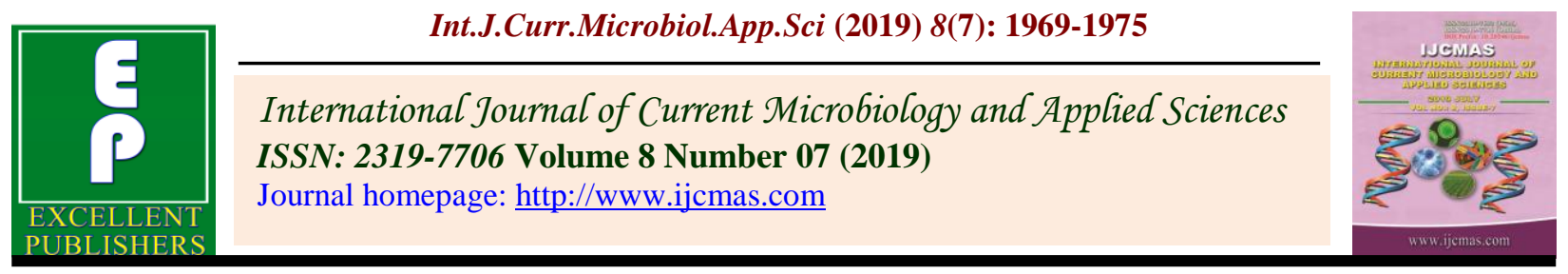

Original Research Article

https://doi.org/10.20546/ijcmas.2019.807.234

\title{
Assessment of Genetic Diversity in Gangatiri Cow by Employing RAPD Marker
}

\author{
Ngangkham James Singh ${ }^{1}$, Ram Pal Singh ${ }^{1}$, Neeraj ${ }^{1}$, \\ Prashant Ankur Jain ${ }^{2}$ and Balvir Singh ${ }^{3}$ \\ ${ }^{1}$ Department of Animal Husbandry and Dairying, ${ }^{2}$ Department of Computational Biological \\ and Informatics, SHUATS, Allahabad 211007, India \\ ${ }^{3}$ UPCAR, Lucknow, India \\ *Corresponding author
}

\begin{tabular}{|l|}
\hline Ke y w o r d s \\
RAPD, Genetic \\
diversity, \\
$\begin{array}{l}\text { Fingerprints, } \\
\text { Phylogenetic }\end{array}$ \\
\hline Article Info \\
\hline $\begin{array}{l}\text { Accepted: } \\
\text { 15 June } 2019 \\
\text { Available Online: } \\
\text { 10 July } 2019\end{array}$ \\
\hline
\end{tabular}

A B S T R A C T

Random amplified polymorphic DNA- Polymerase chain reaction (RAPDPCR) was employed to assess the genetic variability and phylogenetic relation among fifteen breed of Gangatiri animals Viz. fourteen animals (cow no.288, 348, 394, 365, 313, 364, 293, 319, 283, 208, 306, 322, 476, 478) are both sexes and one bull were selected randomly. The DNA samples were isolated from a total of fifteen animals from Gangatiri cows and three random primers were selected. The genetic distance was found higher between cow no. 288 and $476(\mathrm{D}=0.82697)$ and lower $(\mathrm{D}=$ 0.17647 ) between cow no 478 and 476 . The phylogenetic tree shows that cow no. 288 and 348 are closer, whereas cow no. 208 and 364 are distant to each other. The level of diversity as evident in these mutants can be harnessed in breeding for better varieties as the divergent genotypes are expected to result in high heterosis. The unique allele can be harnessed for genotype identity.

\section{Introduction}

Gangatiri is an indigenous dual purpose cattle breed of India It is originated in the region along the banks of Ganga River in eastern Uttar Pradesh and western part of Bihar state. The breeding tract of this breed includes mainly Ballia and Ghazipur districts of Uttar Pradesh, Rohtas and Shahabad districts of
Bihar. Population of Gangatiri cattle in Uttar Pradesh is 364.81 thousand out of this population, Mirjapur district is having highest population with 23.11 thousand cattle and 13.15 thousand Gangatiri cattle are found in Varanasi district as per the report of Uttar Pradesh State Biodiversity Board (2015). This is an important dual purpose breed of Northern part of India These cattle are well 
adapted and medium input production system and produce 2.5 to 8.0 liter milk per day. Animal are rearing for milk production as well as ploughing, thrashing and power works. The lactation length is 150-250 days. Inter-calving period varies from 14-24 months. Gangatiri cattle are dual purpose indigenous cattle breed with good draught capacity. The average milk production of Gangatiri is 4.5 1/day and fat per cent varies from 4.1 to $5.2 \%$ (Anonymous 2006). Gangatiri is native of duaba area falling between Ganga and Ghaghara rivers. This is a medium size cattle breed reared mainly by resource poor farmers on zero or low input system for their livelihood (Singh et al., 2007). A livelihood is socially sustainable when it can cope with and recover from stress and shocks and provide for future generations (Chambers and Conway, 1992).

Sustainable agriculture may be regarded as successful management of resources for agriculture to satisfy the changing human needs while maintaining or enhancing the quality of environment and conserving natural resources (FAO 1991). The breed significantly contributes to the liveliness of the people due to its good dual purpose. Polymorphic genetic markers are extremely useful for a number of application such as measurement of the amount of genetic diversity in species, discrimination between individual, strains or species, identification of markers linked to economically useful traits as well as analyses of animal kinship relationship, behavioral and population ecology. Random amplified polymorphic DNA- polymerase chain reaction technique has been used for estimation of the genetic variability among the breeds. RAPD markers are the randomly amplified target region of less functional part of the genome that does not strongly respond to selection on the phenotypic level. Such amplified region might accumulate more mutations, thereby offering a wider potential in assessing the intra/interbred genetic differentiation. The
RAPD -PCR has been used to estimate the genetic variability among livestock species. In the case of cattle, lots of researchers have been made to detect DNA polymorphisms between cattle breeds by RAPD analysis during last decades. Especially genetic marker for native cattle in several countries were investigated for the improvement of their native cattle, including Japanese black cattle, German native cattle, Zebu cattle, Bos indicus and Bos Taurus. Considering the above statement the present research work on "Assessment of genetic diversity of Gangatiri cow by employing random amplified polymorphic DNA (RAPD) markers" was undertaken to know the genetic diversity and relationship among Gangatiri cattle.

\section{Materials and Methods}

The experiment was carried out at the Micelles Life Science (Pvt.) Ltd., 4/462, Vibhav Khand, Gomti Nagar Lucknow, U.P. The details of materials and methods used are described as follows.

The total of fifteen animal of Gangatiri cows were selected from Department of Animal Husbandry and Dairying SHUATS. $5 \mathrm{ml}$ of blood was collected from each animal in a10 ml EDTA vacationer tube and kept in ice box during collection and then transported to the laboratory and stored at $-20^{\circ} \mathrm{C}$ until the isolation of genomic DNA. The cattle identification numbers are given in table 1 .

\section{Extraction of genomic DNA from blood samples}

DNA was extracted from blood by MLS blood genomic DNA kit protocol. The present of DNA in the extracted sample was confirmed by running the sample in a $1 \%$ agarose gel at $80 \mathrm{~V}$ for 48 minutes. The quality of DNA was measured by spectrophotometer at $260 \mathrm{~nm}$ wavelength. 


\section{PCR reaction}

\section{Primer selection}

In this study three universal RAPD primers were selected. List of the primers along with their sequences are shown in table 2.

\section{PCR amplification}

PCR reaction were performed on each DNA sample in a $25 \mu 1$ reaction mix containing

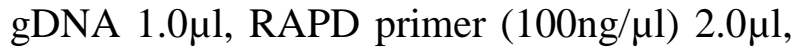
dNTPs $(10 \mathrm{mM})$ 1.0 $\mu$ l, TaqPol Assay buffer

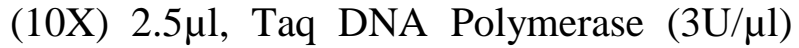
$0.5 \mu 1$ and water $18 \mu \mathrm{l}$. DNA amplification was performed by thermal cycle. The amplification program included an initial denaturation step of $94^{\circ} \mathrm{C}$ for 5 minutes followed by 40 cycles of $94^{\circ} \mathrm{C}$ denaturation 1 minute, $54^{\circ} \mathrm{C}$ annealing $1 \mathrm{~min}$, and $72^{\circ} \mathrm{C}$ extension for 2 minutes. The final extension was performed at $72^{\circ} \mathrm{C}$ for 15 minutes and held at $8^{\circ} \mathrm{C}$.

\section{Gel electrophoresis of PCR amplified product}

Prepare 1X TBE by diluting appropriate amount of 10X TBE buffer. Weigh $0.5 \mathrm{~g}$ of agarose and add to $50 \mathrm{ml}$ of $1 \mathrm{X}$ TBE. This given $1 \%$ agarose gel. Boil till agarose dissolved completely and a clear solution results. Add ethidium bromide to molten agarose to a final concentration of $0.5 \mu \mathrm{g} / \mathrm{ml}$ (from a stock of $10 \mathrm{mg} / \mathrm{ml}$ in water), when temperature is $50^{\circ} \mathrm{C}$. Meanwhile place the combs of electrophoresis set such that it was approximately $2 \mathrm{~cm}$ away from the cathode. Pour the agarose solution in the central part of the tank (the thickness of the gel should be 0.5 $-0.9 \mathrm{~cm}$ ). Keep the gel undisturbed at room temperature for the agarose to solidify. Pour 1X TBE buffer into the gel tank till the buffer level stands at $0.5-0.8 \mathrm{~cm}$ above the gel surface. Gently lift the combs ensuring that the wells remain intact. Connect the power cord to the electrophoretic power supply according to the convention, red - anode and black cathode. Mix $5 \mu 1$ of gel loading buffer with $15 \mu 1$ of the sample and load the wells. Set the voltage to $50 \mathrm{~V}$ and switch on the power supply. Switch off the power supply when the tracking (Bromophenol blue) from the well reaches $3 / 4$ of the gel. Observe the bands under UV transilluminator for checking the DNA bands and photographed using a digital camera (Fig. 1).

\section{Data analysis}

Only distinct and prominent band were scored for estimation of various parameters. The presence and absence of band was recorded as "1" and " 0 " respectively. The binary coded characters $(1,0)$ were used for genetic analysis. Statistical analyses were carried out for estimation of genetic distance, identity and phylogenetic relationship among 15 breed of Gangatiri cow. The relationship among breeds of Gangatiri cow was analyzed by generating dendogram using Nei genetic distances with UPGMA (Un- weighed pair group method using arithmetic average) analysis through PHYLIP software.

\section{Results and Discussion}

The DNA fragment to be enlarged is determined by selecting primers. Primers are short, artificial; DNA strand often nor more than 50 and usually only 17 to 22 base pair long that are complimentary to the beginning or the end of the DNA section to be enlarged. They are extremely rich in the genomes of eukaryotes, polymorphic and more often than not co-dominant and manageable among dissimilar mapping populations. The variation in band profile was observed within the breed however most of the bands were not variable between individuals $\mathrm{f}$ the same breed. The majority of RAPD primer gave distinctly reproducible bands in all the breeds some of 
the primer produced highly polymorphic patterns, but other produced less polymorphic products. The band profile was found similar to the study of Appa Rao et al., who reported that the variations may exist between individual of same species.

The genetic distances between breeds were calculated using Nei equation through POPGENE software (Table 3). In the present study an individual primer produced more variable results as compared to results obtained by all primers hence all primer data were pooled for estimation of genetic parameters. Neighbor-joining method is proposed for reconstructing phylogenetic trees from evolutionary distance data. The principle of this method is to find pairs of operational taxonomic units (OTUs [= neighbors]) that minimize the total branch length at each stage of clustering of OTUs starting with a star like tree. Cow no. 476 and 348 has maximum distance value 0.82697 and 478 and 476 has minimum distance value 0.17647 .

Table.1 Cattle's identification numbers and sex

\begin{tabular}{|l|l|}
\hline Code & Cow Name \\
\hline 1 & 288 \\
\hline 2 & 348 \\
\hline 3 & 394 \\
\hline 4 & 365 \\
\hline 5 & 313 \\
\hline 6 & 364 \\
\hline 7 & 293 \\
\hline 8 & 319 \\
\hline 9 & 283 \\
\hline 10 & 208 \\
\hline 11 & 306 \\
\hline 12 & 322 \\
\hline 13 & 476 \\
\hline 14 & 478 \\
\hline 15 & Bull \\
\hline
\end{tabular}

Table.2 List and sequences of primer used in the experiment

\begin{tabular}{|c|c|c|}
\hline S. N. & Primer & GC \% \\
\hline Primer 1 & 5'-CCCHGCAMCTGMTCGCACHC - 3' & $60 \%$ \\
\hline Primer 2 & 5'-AGGHCTCGATAHCMGVY - 3' & 41.18 \\
\hline Primer 3 & 5'-MTGTAMGCTCCTGGGGATTCHC - 3' & $50 \%$ \\
\hline
\end{tabular}


Table.3 Estimation of pair wise genetic distance between experimental Gangatiri cattle using Nei's equation

\section{Distance Matrix Table RAPD}

\begin{tabular}{|c|c|c|c|c|c|c|c|c|c|c|c|c|c|c|c|}
\hline \multicolumn{8}{|c|}{ A - Nei and Li/Dice } & \multicolumn{8}{|l|}{$=$} \\
\hline \multicolumn{16}{|c|}{$\begin{array}{l}\text { Tree-construction method } \\
\sim \text { UPGMA }\end{array}$} \\
\hline & 288 & 348 & 394 & 365 & 313 & 364 & 293 & 319 & 283 & 208 & 306 & 322 & 478 & 478 & BULL \\
\hline 288 & & 0.21865 & 0.62724 & 0.64851 & 0.62007 & 0.61724 & 0.61433 & 0.61806 & 0.62963 & 0.61775 & 0.74661 & 0.76056 & 0.82045 & 0.81955 & 0.73483 \\
\hline 348 & 0.21865 & & 0.62909 & 0.60784 & 0.63636 & 0.63636 & 0.60208 & 0.64437 & 0.63148 & 0.60900 & 0.74194 & 0.75120 & 0.82697 & 0.82609 & 0.73913 \\
\hline 394 & 0.62724 & 0.62909 & & 0.42857 & 0.40741 & 0.42126 & 0.39689 & 0.41270 & 0.38586 & 0.33852 & 0.74054 & 0.80226 & 0.79939 & 0.81040 & 0.74263 \\
\hline 365 & 0.64951 & 0.60781 & 0. 42857 & & 0.34809 & 0.33333 & 0.28381 & 0.27379 & 0.34387 & 0.230 .48 & 0.72703 & 0.77534 & 0.78235 & 0.78107 & 0.74479 \\
\hline 313 & 0.62007 & 0.63636 & 0.40741 & 0.34809 & & 0.31890 & 0.38132 & D. 29762 & 0.34545 & 0.31907 & 0.71351 & 0.74011 & 0.75684 & 0.77982 & 0.72118 \\
\hline 364 & 0.61724 & 0.63636 & 0.42126 & 0.33333 & 0.31890 & & 0.28731 & 0.34981 & 0.35010 & 0.28358 & 0.75000 & 0.78723 & 0.80057 & 0.82235 & 0.76709 \\
\hline 293 & 0.61433 & 0.60208 & 0.39689 & 0.28381 & 0.38132 & 0.28731 & & 0.34962 & 0.30784 & 0.26199 & 0.74874 & 0.75916 & 0.79272 & 0.80282 & 0.74065 \\
\hline 319 & 0.61806 & 0.64437 & 0.41270 & 0.27379 & 0.29762 & 0.34981 & 0.34962 & & 0.42300 & 0.32707 & 0.73711 & 0.77957 & 0.79827 & 0.79130 & 0.72890 \\
\hline 283 & 0.62963 & 0.63148 & a.38586 & 0.31387 & 0.34515 & 0.35010 & 0.30784 & 0.42300 & & 0.26960 & 0.73615 & 0.77410 & 0.77515 & 0.79762 & 0.73298 \\
\hline 208 & 0.61775 & 0.60900 & a.33852 & 0.23048 & 0.31907 & 0.28358 & 0.26199 & 0.32707 & 0.26960 & & 0.72864 & 0.77487 & 0.77031 & 0.79155 & 0.74065 \\
\hline 306 & 0.74661 & 0.74194 & 0.74054 & 0.72703 & 0.71351 & 0.75000 & 0.74874 & 0.73711 & 0.73615 & 0.72864 & & 0.32773 & 0.24883 & 0.30806 & 0.31518 \\
\hline 322 & 0.76056 & 0.75120 & 0.80226 & 0.77534 & 0.74011 & 0.78723 & 0.75916 & 0.77957 & 0.77410 & 0.77487 & 0.32773 & & 0.37056 & 0.35385 & 0.36100 \\
\hline 476 & 0.82045 & 0.82697 & 0.79939 & 0.78235 & 0.75684 & 0.80057 & 0.79272 & 0.79827 & 0.77515 & 0.77031 & 0.24883 & 0.37056 & & 0,17647 & 0.36111 \\
\hline 478 & 0.81955 & 0.82609 & a.81040 & 0.78107 & 0.77982 & 0.82235 & 0.80282 & 0.79130 & 0.79762 & 0.79155 & 0.30806 & 0.35385 & 0.17647 & & 0.39252 \\
\hline BULL & 0.73483 & 0.73913 & 0.74263 & 0.74479 & 0.72718 & 0.76709 & 0.74065 & 0.72890 & 0.73298 & 0.74065 & 0.31518 & 0.36100 & 0.36111 & 0.39252 & \\
\hline
\end{tabular}

Fig.1 Genomic DNA extracted from 15 blood samples loaded on 1\% agarose gel lanes
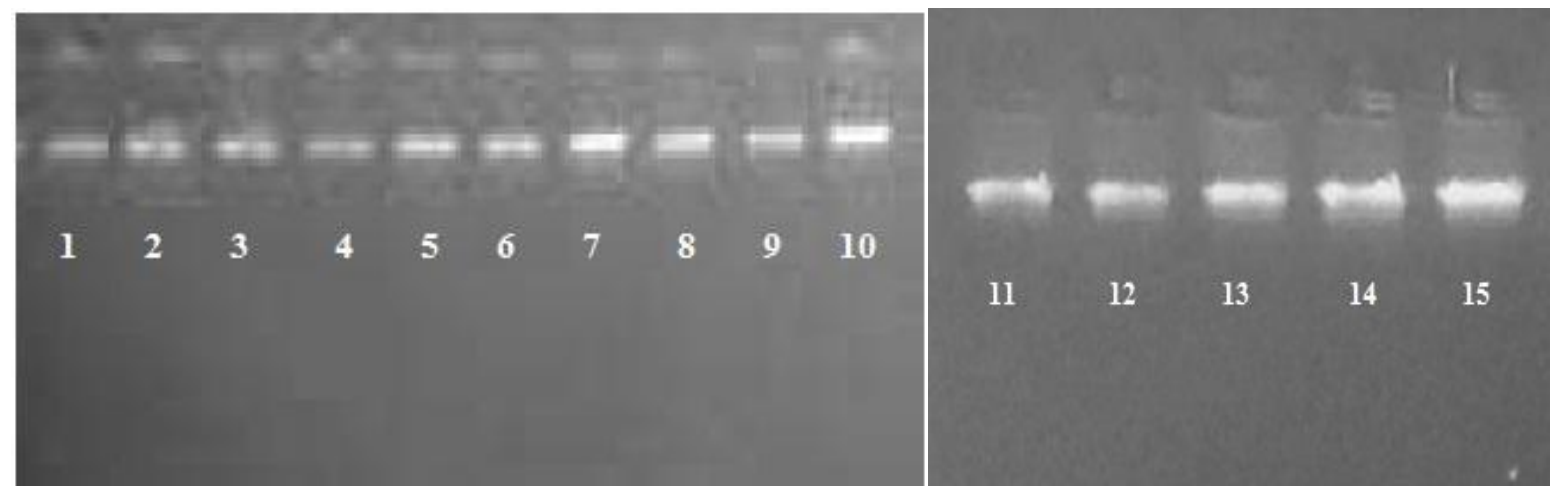

1 to $10-$ gDNA of Samples 1 to 10 and Lanes 11 to $15-$ gDNA of Samples 11 to 15 .

Fig.2 Phylogenetic relationship among breed of Gangatiri based on RAPD pooled data from three primer using UPGMA analysis through neighbor procedure of phylip version 3.5

(POPEGENE software)

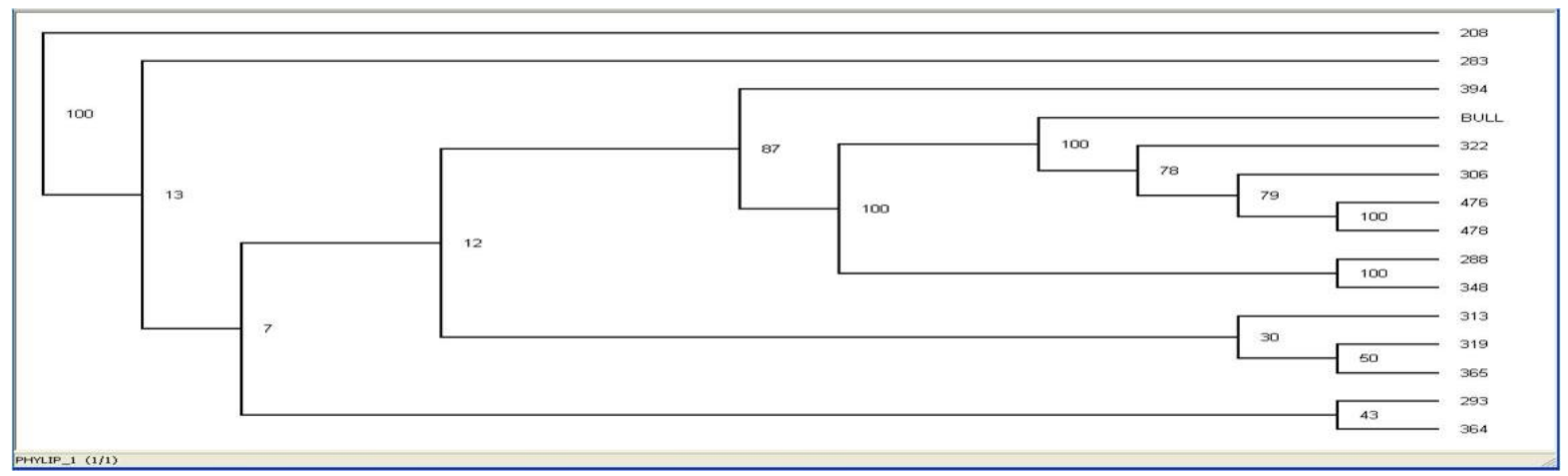


The phylogenetic relationship among these breeds was revealed through the UPMA dendogram base on Nei's genetic distance through POPGENE software (Fig. 2). Visualization of breed relationship using $\mathrm{NJ}$ tree obtained from Nei's genetic distance shows clustering of breeds in conformity to the geographic location of populations. The result show that cow no. 476 and 478 are closely related similarly cow no. 288 and 348 are also closely related to each other. Nearest distance as per tree from bull is cow no. 322 and largest distance is 208 .

Genetic diversity is of great significance for breeding program. Germplasm characterization is an important component of programmes on effective and efficient management, utilization of animal genetics resources. RAPD markers are randomly distributed throughout the genome, but most reason of the genome is not expressed at the phenotypic level. As a result marker like RAPD may accurately assay the degree of genetic change between two genomes but they may not necessarily reflect the divergence in term of changes in traits of livestock improvement. The differences of genetic variations in the present study found in fifteen experimental cattle samples were high and therefore, there is a scope for future improvement of local cattle. More research needs to be done on the native cattle and the choice of cattle for conservation must take into account any available information on productivity traits of economic value.

This study reveals the phylogenetic relationship among these mutants and their parents. The exotic line was different from the rest with the three molecular markers, indicating the difference in their pedigree and geographical origin. Cow no. 476 and 348 has maximum distance value 0.82697 and 478 and 476 has minimum distance value 0.17647 . The result obtained here will be useful for breeders who are willing to explore the possibility of pyramiding genes that are responsible for rose like flower mutations, reduced petal mutation and others studied. The level of diversity as evident in these mutants can be harnessed in breeding for better varieties as the divergent genotypes are expected to result in high heterosis. The unique allele can be harnessed for genotype identity. From the clustering pattern and genetic relationship obtained using RAPD markers, breeders can identify the diverse from different cluster and employ them in their future breeding prorammes for the selection of parents to generate mapping populations.

\section{References}

Adel E El-tarras1, Ahmad F. Shahaby and Abdel Elah Banaja (2015). Assessment of Genetic Diversity in Saudi Goats, Saudi Arabia Using Genetic Finger printing. Int.J.Curr.Microbiol.App.Sci 4(4): 223231

Anonymous. 2006. Cattle Genetic Resources of India: Gangatiri. Research Bulletin, Network Project on Animal Genetic Resources, ICAR, New Delhi, India.

Basant Kumar Bhinchhar, Vinod Kumar Paswan, Saroj, Satya Prakash Yadav and Prity Singh (2017). Characterization of Gangatiri cattle breed in Gangatic plains of Eastern Uttar Pradesh, India. Indian J. Anim. Res., 51 (6) 2017: 988-992.

Chambers R and Conway G R. 1992. Sustainable rural livelihood: practical concepts for the 21st century. IDS discussion paper 296, Brighton.

FAO. 1991. Sustainable Agriculture and Rural Development in Asia and Pacific. Regional development No. 2, FAO/ Netherlands conference on agriculture and environment, 5- heterogenbosch, The Netherlands, April, pp. 15-19.

Hafiz Muhammad Waheed, Safdar Ali, Muhammad Sajjad Khan, Muhammad Said ur Rehman and Ghulam Abbas 2015. 
"Molecular Genetic Variations among Some Punjab Sheep Breeds Using RAPD Analysis". Advances in Zoology and Botany 3(1): 15.

M. De Marchi, C. Dalvit, C. Targhetta and M. Cassandro (2006). Assessing genetics diversity in indigenous Veneto chick breeds using AFLP markers. Animal Genetics, 37: 101-105.

M.L. Sangwan (2012). Analysis of Genetic Diversity of Indian Buffalo Breeds by DNA Markers. Journal of Buffalo Science. 1: 91-101.

MM Khanam, MK Islam, KM Hossain, SMM Rahman, J Jasmin and M Ahmed 2015. "molecular characterization of selected local cattle using random amplified polymorphic DNA (RAPD) markers ". Eco-friendly Agril. J. 8(03): 16-23.

Mollah MBR, Islan MS, Ali MA, and Alam Ms (2009). Analysis of genetic diversity in Bangladeshi chicken using RAPD markers. Biotechnology, 8: 462-467.

Ogah D. M and O. M. Momoh (2014). Analysis of Genetic Diversity of Nigeria Indigenous Muscovy Duck Ecotypes using RAPD Marker. Production Agriculture Technology. 10: 225-232.

Puspendra Kumar Singh, G Sankhala, Amit Singh and Kamta Prasad (2016) Sustainability of Gangatiri cattle rearing. Indian Journal of Animal Sciences 86 (8): 936-939,

Rangoju P.K., Kumar S., Kolte A.P. Gulyani R., Singh V.K 2007. Assessment of genetic variability among rabbit breeds by random amplified polymorphic DNA (RAPD)-PCR. World Rabbit Sci. 2007, $15: 3-8$.

Rekha Sharma, A. K. Pandey, Y. Singh, B. Prakash, B. P. Mishra, P. Kathiravan, P.
K. Singh and G. Singh. 2009. Evaluation of Genetic Variation and Phylogenetic Relationship among North Indian Cattle Breeds. Asian-Aust. J. Anim. Sci. 22(1):13-19.

Rekha Sharma, A. K. Pandey, Y. Singh, B. Prakash, B. P. Mishra, P. Kathiravan, P. K. Singh and G. Singh. 2009. Evaluation of Genetic Variation and Phylogenetic Relationship among North Indian Cattle Breeds. Asian-Aust. J. Anim. Sci. 22(1):13-19

S Kumar, A P Kolte, B R Yadav, Sushil Kumar, A.L Arora and V.K Singh 2008. "Genetic variability among sheep breeds by random amplified polymorphic DNAPCR". Indian Journal of Biotechnology Vol. 7 pp: 482-486.

Sharma, D., K.B.C. Appa Rao, R.V. Singh and S.M. Totel, (2001). Genetic diversity among chicken breed estimated through randomly amplified polymorphic DNA. Animal Biotechnology 12: 111-120.

Sodhi, M., Mukesh, M., Anand A., Bhatia, S. and Mishra, B.P (2006). Assesment of genetic variability in two north India buffalo breed using Random Amplified Polymorphic DNA (RAPD) marker. Asian- Australasian Journal of Animal Sciences. 19: 1234-1239.

Tarik S.K.M. Rabie and A.M Abvdou (2010). Genetic diversity and relationship among Egyptian indigenous chicken strain using random amplification of polymorphic DNA Egypt. Poultry Science. 30:473-482

Uttar Pradesh State Biodiversity Board, Lucknow, U.P., India. (2015). Official website www.upsbdb.org/pdf/20121017/

FLYERS/ 5.GangatiriCattle.pdf, 2015.

\section{How to cite this article:}

Ngangkham James Singh, Ram Pal Singh, Neeraj, Prashant Ankur Jain and Balvir Singh. 2019. Assessment of Genetic Diversity in Gangatiri Cow by Employing RAPD Marker. Int.J.Curr.Microbiol.App.Sci. 8(07): 1969-1975. doi: https://doi.org/10.20546/ijcmas.2019.807.234 